\title{
Childhood socioeconomic status and risk of cardiovascular disease in middle aged US women: a prospective study
}

\author{
Michael D Gliksman, Ichiro Kawachi, David Hunter, Graham A Colditz, \\ JoAnn E Manson, Meir J Stampfer, Frank E Speizer, Walter C Willett, \\ Charles H Hennekens
}

\begin{abstract}
Objective - To examine prospectively the relationship of childhood socioeconomic status and risk of cardiovascular disease in middle aged women.

Design - A prospective cohort of women with 14 years follow up data (1976-90).

Subjects - A total of 117006 registered female nurses aged 30 to 55 years in 1976 and free of diagnosed coronary heart disease, stroke, and cancer at baseline.

Main outcome measures - Incident fatal coronary heart disease, non-fatal myocardial infarction, and stroke (fatal and non-fatal).
\end{abstract}

Results - Low socioeconomic status in childhood was associated with a modestly increased risk of incident non-fatal myocardial infarction and total cardiovascular disease in adulthood. Compared with middle aged women from white collar childhood backgrounds, the age adjusted risk of total cardiovascular disease for women from blue collar backgrounds was $1 \cdot 13(95 \%$ CI $1 \cdot 02,1 \cdot 24)$ and that of nonfatal myocardial infarction was $1 \cdot 23(95 \%$ CI $1 \cdot 06,1 \cdot 42)$. No significant increase in risk was observed for stroke or fatal coronary heart disease. Adjustment for differences in family and personal past medical history, medication use, exercise, alcohol intake, diet, birth weight, being breastfed in infancy, and adult socioeconomic circumstance somewhat attenuated the increased risks observed for women from blue collar childhood socioeconomic backgrounds. In multivariate analysis, women whose fathers had been manual labourers had the highest relative risk of total coronary heart disease $(\mathbf{R R}=$ $1 \cdot 53$; $95 \%$ CI $1 \cdot 09,2 \cdot 16)$ and non-fatal myocardial infarction $(R R=1 \cdot 67 ; 95 \%$ CI $1 \cdot 11$, $2 \cdot 53)$ when compared with women whose fathers had been employed in the professions.

Conclusion - In this group lower childhood socioeconomic status was associated with a small but significant increase in the risk of total coronary heart disease as well as non-fatal myocardial infarction. For women from the most socioeconomically disadvantaged childhood backgrounds, the association is not explained by differences in a large number of cardiovascular risk factors, by differences in adult socioeconomic status, or by differences in indices of nutrition during gestation or infancy.

\section{(f Epidemiol Community Health 1995;49:10-15)}

Low socioeconomic status is associated with increased morbidity and mortality. These differences are most evident in the very young as well as those over 65 years of age, especially after the exclusion of occupationally related deaths. ${ }^{12}$ Socioeconomic status is also associated with differences in cardiovascular disease incidence ${ }^{3}$ and coronary heart disease mortality. ${ }^{4}$ An inverse relationship between socioeconomic status and risk of stroke and coronary heart disease has been reported in several prospective studies. ${ }^{5}$ Furthermore, the decline in mortality from cardiovascular disease in western societies over the past two decades has been most evident in higher socioeconomic groups. ${ }^{6}$ The mechanisms underlying these associations are not clear but have been the subject of recent research.

Risk factors for cardiovascular disease are more prevalent among children and adults from lower socioeconomic backgrounds. ${ }^{7-9}$ Social class differences in diet and physical activity in children have been described. ${ }^{410}$ In addition, previous studies of childhood socioeconomic status and risk of cardiovascular disease have failed to address adequately the problem of confounding by achieved adult socioeconomic status. For these reasons, it remains unclear whether childhood status is independently linked to risk of cardiovascular disease in adulthood. ${ }^{11}$

The nurses' health study offers a unique opportunity to address these issues among women. Baseline data allowed the assignment of childhood socioeconomic status. Variability in achieved socioeconomic status of this cohort is less than in the general population. All female nurses qualify for the same socioeconomic status rating as adults on the Duncan scale, ${ }^{12}$ which is independent of marital status and occupation of spouse.

In this report we assess whether there is a relation between childhood socioeconomic status and risk of cardiovascular disease in a large cohort of US female nurses after adjustment for a large number of cardiovascular risk factors, including sociodemographic variables.

\section{Methods}

The nurses' health study cohort was established 
in 1976 when 121700 registered female nurses 30-55 years of age, residing in 11 US states, completed lifestyle and medical history questionnaires sent by mail. Approximately $98 \%$ of the cohort is white. ${ }^{13}$ Biennial follow up questionnaires sent by mail update information on life events, cardiovascular risk status, cardiovascular disease, and other health related events. At baseline all women who reported coronary heart disease, stroke, or cancer (other than non-melanoma skin cancer) were excluded, leaving a cohort of 117006 women available for follow up.

In 1980 , a validated, semiquantitative food frequency questionnaire as well as questions assessing physical activity were added to the follow up and have been updated regularly. ${ }^{1415}$ A total of 88366 nurses free of prevalent cardiovascular disease or cancer completed and returned the 1980 diet questionnaire.

In the 1992 questionnaire 88968 participants completed information on their birth weight, whether they were breastfed as infants and, if currently married or widowed, their husband's highest educational attainment.

\section{EXPOSURE DATA}

In 1976 each woman was asked to state the occupation of her parents when she was aged 16 years, in a form that allowed coding of responses consistent with the USA census book codes for occupations. ${ }^{16}$ This classification, which has been used by the Census Bureau since $1940,{ }^{17}$ assigns each subject to one of eight separate categories (listed below). These categories correlate strongly with socioeconomic status ratings calculated by the validated method devised by Duncan ${ }^{1217}$ for the population of the USA at a time contemporary to the childhood and youth of the members of the nurses' health study cohort. This method specifically correlates with household income and occupational prestige, variables which indicate educational and other environmental opportunities available to children. ${ }^{17}$

The only exception is for the category "farmer". The Duncan score is said to underestimate their true economic wellbeing which is enhanced by an active "barter" economy. 121617 These categories (listed in descending order by Duncan's socioeconomic score) are as follows:

(1) Professional/technical;

(2) Managers/officials/proprietors;

(3) Clerical and kindred workers;

(4) Skilled blue collar;

(5) Semi-skilled blue collar;

(6) Domestic and service workers;

(7) Farmers/farm workers;

(8) Labourers (except farm workers).

To increase statistical power while retaining the validity of the measure of childhood socioeconomic status, these categories were consolidated into three groups - white collar (categories 1, 2, 3), blue collar (categories 4, $5,6,8$ ), and farmer (category 7 ). Childhood socioeconomic status was assigned on the basis of the father's occupation, a method comparable with previously published studies. ${ }^{18}$ Of the remainder, the father was either unemployed, retired, or his occupational status could not be determined. All women whose fathers were known to be dead by the time each woman was 16 years old were placed in the "father deceased" category. This was determined by an algorithm which compared the father's date of death with the study participant's date of birth. Only 1861 women did not supply sufficient information to enable their classification into one of these four categories.

In 1976 and 1984, participants were asked whether their father or mother had suffered a myocardial infarction and if so, at what age. If a participant indicated that either or both parents had suffered an infarction before age 60 years, the participant was considered to have a positive parental history of early onset myocardial infarction.

In 1992, participants who were currently married or widowed were asked to indicate their husband's highest level of education. A total of 6649 women were divorced and were not asked to complete this question. Education levels are highly correlated with socioeconomic status. ${ }^{19}$ Responses were categorised as no high school, some high school, high school graduate, college graduate, graduate school. Of the 88968 women who completed the 1992 questionnaire, 74668 indicated they were either currently married or were widowed. Of these, all but 163 provided information of their husband's educational attainment.

In 1976, cigarette smoking was categorised as never, former, and current, with current smokers categorised as 1-14 cigarettes/d, $15-24 / d, 25+/ d$. Information on smoking status was updated biennially. Questions about physician-diagnosed hypertension, hypercholesterolaemia, and diabetes were also first asked in 1976 and updated biennially.

Also in 1976, weight was recorded and then updated in every biennial questionnaire. In a validation study among 184 cohort members living in the Boston area, these self reported weights correlated highly with those measured by a technician. ${ }^{20}$ Height was taken from the 1976 questionnaire. Body mass index was calculated as weight (in $\mathrm{kg}$ ) divided by the height (in $\mathrm{m}^{2}$ ) and was categorised into quintiles.

In 1980 , a history of regular aspirin use was obtained and updated biennially. We calculated the average number of tablets or capsules taken per week and categorised aspirin use as $<1$ aspirin per wk, 1-6/wk, >6/wk. In 1976, information on postmenopausal hormone and oral contraceptive use was collected and updated biennially. Hormone replacement therapy and oral contraceptive use were categorised as current, past, or never.

The 1980 questionnaire inquired about the frequency of vigorous exercise. Activity levels were assessed by the number of "sweat inducing" exercise sessions per week. This method has been validated in several studies. ${ }^{21-23}$ We divided the cohort into those women who exercised vigorously at least once per week, and those who did not.

Also in 1980, alcohol intake was assessed in the semiquantitative food frequency ques- 
tionnaire. Alcohol consumption was updated in 1984 and then biennially. Daily alcohol consumption was categorised as nil, $1-4.9 \mathrm{~g} / \mathrm{d}$, $5-14.9 \mathrm{~g} / \mathrm{d},>14.9 \mathrm{~g} / \mathrm{d}$. In this cohort the validity of self reported alcohol intake is high. ${ }^{2425}$

Dietary intake of trans fatty acids is associated with the risk of incident coronary heart disease.$^{26}$ For the current analysis, the energy adjusted dietary intake of trans fatty acids was assessed and divided into quintiles. Vitamin E intake is also associated with the risk of incident coronary heart disease. ${ }^{27}$ As much of the observed benefit was attributable to oral vitamin E supplementation, quantification of intake for the current analysis included oral supplements. Vitamin $\mathrm{E}$ intake was categorised by quintiles.

In the 1992 questionnaire, participants reported whether they had been breastfed as infants. Responses fell into one of the categories "yes", "no", or "don't know". Of the 87917 women who answered this question, 14586 indicated they "don't know". In the same questionnaire, they were also asked to indicate if their birth weight (in lb) fell within the categories: not sure; $<5 ; 5$ to $5 \cdot 5 ; 5 \cdot 5+$ to $7 ; 7+$ to $8 \cdot 5 ; 8 \cdot 5+$ to $10 ; 10+$. Of the 87314 women who answered this question, 16924 indicated they were "not sure".

\section{ASCERTAINMENT OF CARDIOVASCULAR OUTCOMES}

Reports of non-fatal and fatal cardiovascular outcomes were assessed by standard methods ${ }^{28}$ which included physician review of medical records. A diagnosis of myocardial infarction was confirmed if the relevant World Health Organization criteria were met. ${ }^{29}$ These require the presence of symptoms and either typical electrocardiograph changes or elevation of cardiac enzymes. Medical records to validate reports of coronary artery bypass grafting were obtained for events dating from 1978 onwards. $^{30}$

A diagnosis of stroke was confirmed if the event was characterised by a typical neurological defect of rapid or sudden onset, lasting at least 24 hours and attributable to a cerebrovascular event which was not secondary to infection or neoplasia. Subdural haematomas were excluded from analysis. Total non-fatal

Table 1 Age standardised relative risks (95\% CI) of cardiovascular diseases by childhood socioeconomic status 1976-90

\begin{tabular}{|c|c|c|c|c|}
\hline & White collar & Blue collar & Farmer & Father deceased* \\
\hline No of women & 41225 & 54396 & 9764 & 9760 \\
\hline $\begin{array}{l}\text { Person years exposure } \\
\text { Cardiovascular diseaset: }\end{array}$ & 563577 & 742515 & Cardiovascular disease $\dagger$ : & 131024 \\
\hline Total RR(CI) & $1 \cdot 00$ & $1 \cdot 13(1 \cdot 03,1 \cdot 24)$ & $0 \cdot 89(0 \cdot 75,1 \cdot 06)$ & $1 \cdot 23(1 \cdot 05,1 \cdot 44)$ \\
\hline Non-fatal & $1 \cdot 00$ & $1 \cdot 17(1 \cdot 04,1 \cdot 31)$ & $0.92(0 \cdot 76,1 \cdot 12)$ & $1 \cdot 28(1 \cdot 08,1 \cdot 54)$ \\
\hline Fatal & $1 \cdot 00$ & $1 \cdot 03(0 \cdot 86,1 \cdot 24)$ & $0 \cdot 81(0 \cdot 59,1 \cdot 11)$ & $1 \cdot 14(0 \cdot 85,1 \cdot 53)$ \\
\hline \multicolumn{5}{|l|}{ Coronary heart disease: } \\
\hline $\begin{array}{l}\text { Total RR(CI) } \\
\text { Non-fatal MI }\end{array}$ & $1 \cdot 00$ & $1 \cdot 17(1 \cdot 03,1 \cdot 33)$ & $0 \cdot 85(0 \cdot 69,1 \cdot 06)$ & $1 \cdot 29(1 \cdot 06,1 \cdot 57)$ \\
\hline $\begin{array}{l}\text { Non-fatal MI } \\
\text { (Cases) }\end{array}$ & $\begin{array}{c}1 \cdot 00 \\
(285)\end{array}$ & $\begin{array}{c}1 \cdot 23(1 \cdot 06,1 \cdot 42) \\
(481)\end{array}$ & $\begin{array}{c}0.93(0 \cdot 72,1 \cdot 19) \\
(81)\end{array}$ & $\begin{array}{c}1 \cdot 35(1 \cdot 08,1 \cdot 69) \\
(102)\end{array}$ \\
\hline $\begin{array}{l}\text { Fatal } \\
\text { (Cases) }\end{array}$ & 1.00 & $1 \cdot 09(0 \cdot 86,1 \cdot 37)$ & $0 \cdot 69(0 \cdot 46,1 \cdot 05)$ & $1 \cdot 20(0 \cdot 84,1 \cdot 72)$ \\
\hline \multicolumn{5}{|l|}{ Stroke: } \\
\hline Total RR(CI) & $1 \cdot 00$ & $1 \cdot 01(0 \cdot 86,1 \cdot 18)$ & $0 \cdot 96(0 \cdot 74,1 \cdot 23)$ & $1 \cdot 17(0 \cdot 91,1.47)$ \\
\hline $\begin{array}{l}\text { Non-fatal } \\
\text { (Cases) }\end{array}$ & $\begin{array}{c}1 \cdot 00 \\
(210)\end{array}$ & $\begin{array}{c}1 \cdot 02(0 \cdot 86,1 \cdot 22) \\
(295)\end{array}$ & $\begin{array}{c}0.95(0 \cdot 71,1 \cdot 26) \\
(61)\end{array}$ & $\begin{array}{c}1 \cdot 22(0 \cdot 93,1 \cdot 60) \\
(68)\end{array}$ \\
\hline $\begin{array}{l}\text { Fatal } \\
\text { (Cases) }\end{array}$ & $\begin{array}{r}1 \cdot 00 \\
(68)\end{array}$ & $0.95(0.69,1 \cdot 30)$ & $0.96(0.57,1.60)$ & $1 \cdot 07(0 \cdot 64,1 \cdot 78)$ \\
\hline & & & & \\
\hline
\end{tabular}

* Father deceased when cohort member was aged 16 years.

t Coronary heart disease and stroke. and fatal cardiovascular disease comprised the sum of non-fatal myocardial infarction and non-fatal stroke, and fatal coronary heart disease and fatal stroke respectively.

Most deaths were reported by relatives or postal authorities. The National Death Index was searched biennially for non-responders. In suspected cases of cardiovascular death, permission to review medical records was sought from the next of kin.

\section{STATISTICAL ANALYSIS}

Incidence rates were computed for non-fatal myocardial infarction and fatal coronary heart disease, non-fatal and fatal stroke, and nonfatal and fatal cardiovascular disease. The cohort at risk included only those who were free of cardiovascular disease at the beginning of each follow up interval.

Rates were obtained by dividing incident cases by person years in each exposure category. All relative risks were age adjusted and $95 \%$ confidence intervals (95\% CI) were calculated. Proportional hazards models were used to evaluate the effects of childhood socioeconomic status while controlling for known and suspected cardiovascular risk factors. When a diagnosis of a cardiovascular end point was made, follow up was stopped.

Where a significant association between socioeconomic status and age adjusted rates of cardiovascular diseases was found, we progressively added known and suspected risk factors for cardiovascular disease $\mathrm{e}^{1326-2831-33}$ to the multivariate models. This was done to determine whether differences in any of these variables provided a plausible explanation for any differences in risk of incident cardiovascular diseases between the childhood socioeconomic status groups.

Only those end points that occurred between the return of the 1976 questionnaire and 1 June 1990 were included in the age adjusted as well as the multivariate analyses. Since information on aspirin, exercise, alcohol intake, and diet were first sought in 1980, multivariate modelling including these variables was restricted to those end points that occurred after that date. In order to compare the effects of the addition of these variables with age adjusted findings, we also calculated age adjusted relative risks for outcomes occurring between 1980 and 1 June 1990.

Since information on spouses' education, participant's birth weight, and breastfed status were collected in 1992, these variables could only be used in models where non-fatal disease was the outcome.

\section{Results}

Between 1976 and 1990 we documented 949 cases of non-fatal myocardial infarction, 364 cases of fatal coronary heart disease, 634 cases of non-fatal stroke, and 194 cases of fatal stroke. In age adjusted analyses (table 1), women from blue collar and "father deceased" childhood backgrounds had a small but significantly increased risk of non-fatal myocardial infarction, 
Table 2 Age standardised relative risks (95\% CI) of cardiovascular diseases by childhood socioeconomic status $1980-90$

\begin{tabular}{|c|c|c|c|c|}
\hline & White collar & Blue collar & Farmer & Father deceased ${ }^{*}$ \\
\hline No of women & 40140 & 52914 & 9499 & 9416 \\
\hline & 3910 & 5146 & 92239 & 91747 \\
\hline Cardiovascular disease $\nmid$ : & 1.00 & $1 \cdot 13(1 \cdot 01,1 \cdot 26)$ & $0 \cdot 94(0 \cdot 78,1 \cdot 13)$ & $1 \cdot 13(0 \cdot 94,1 \cdot 35)$ \\
\hline Non-fatal & 1.00 & $1 \cdot 16(1 \cdot 02,1 \cdot 31)$ & $0 \cdot 98(0 \cdot 79,1$ & $1 \cdot 20(0 \cdot 98,1.47)$ \\
\hline Fatal & $1 \cdot 00$ & $(0 \cdot 85,1 \cdot 29)$ & $0 \cdot 79(0 \cdot 55,1 \cdot 14)$ & $0.93(0.65,1.33)$ \\
\hline \multicolumn{5}{|l|}{ Coronary heart disease: } \\
\hline Total RR(CI) & $1 \cdot 00$ & $1 \cdot 19(1 \cdot 03,1 \cdot 37)$ & $0.92(0 \cdot 71,1 \cdot 17)$ & $1.22(0.97,1.53)$ \\
\hline $\begin{array}{l}\text { Non-fatal MI } \\
\text { (Cases) }\end{array}$ & $\begin{array}{c}1 \cdot 00 \\
(223)\end{array}$ & $\begin{array}{c}1 \cdot 25(1 \cdot 06,1 \cdot 47) \\
(384)\end{array}$ & $\begin{array}{c}1 \cdot 03(0.79,1 \cdot 36) \\
(70)\end{array}$ & $\begin{array}{c}1 \cdot 34(1.03,1 \cdot 73) \\
(79)\end{array}$ \\
\hline $\begin{array}{l}\text { Fatal } \\
\text { (Cases) }\end{array}$ & $\begin{array}{r}1.00 \\
(94)\end{array}$ & $\begin{array}{c}1.07(0.82,1 \cdot 39) \\
(139)\end{array}$ & $\begin{array}{c}0.65(0 \cdot 40,1 \cdot 04) \\
(20)\end{array}$ & $\begin{array}{c}0.93(0.59,1.45) \\
(24)\end{array}$ \\
\hline \multicolumn{5}{|l|}{ Stroke: } \\
\hline Total RR(CI) & $1 \cdot 00$ & $1 \cdot 00(0 \cdot 84,1 \cdot 19)$ & $0 \cdot 96(0 \cdot 73,1 \cdot 27)$ & $1 \cdot 03(0 \cdot 78,1 \cdot 37)$ \\
\hline Non-fatal & $1 \cdot 00$ & $0.98(0.80,1 \cdot 19)$ & $0.93(0.68,1.27)$ & $1 \cdot 03(0 \cdot 75,1 \cdot 42)$ \\
\hline (Cases) & (176) & (236) & (50) & \\
\hline Fatal & $1 \cdot 00$ & $1 \cdot 06(0 \cdot 74,1 \cdot 50)$ & $1 \cdot 05(0 \cdot 60,1 \cdot 84)$ & $0 \cdot 95(0 \cdot 52,1 \cdot 75)$ \\
\hline & & & & \\
\hline
\end{tabular}

* Father deceased when cohort member was aged 16 years.

† Coronary heart disease and stroke.

Table 3 Relative risks (95\% CI) of coronary heart disease by childhood socioeconomic status in multivariate analysis

\begin{tabular}{|c|c|c|c|c|}
\hline & White collar & Blue collar & Farmer & Father deceased ${ }^{*}$ \\
\hline \multicolumn{5}{|c|}{ Non-fatal myocardial infarction } \\
\hline Model 1 & 1.00 & $1 \cdot 19(1 \cdot 03,1 \cdot 38)$ & $1 \cdot 07(0 \cdot 83,1 \cdot 37)$ & $1 \cdot 33(1 \cdot 06,1 \cdot 67)$ \\
\hline 2 & 1.00 & $1 \cdot 19(1 \cdot 03,1 \cdot 38)$ & $1 \cdot 12(0 \cdot 88,1 \cdot 44)$ & $1 \cdot 29(1 \cdot 03,1 \cdot 62)$ \\
\hline $3+$ & 1.00 & $1 \cdot 20(1 \cdot 02,1 \cdot 41)$ & $1.19(0.91,1.56)$ & $1.25(0.98,1 \cdot 61)$ \\
\hline $4+$ & 1.00 & $1 \cdot 18(1 \cdot 01,1 \cdot 39)$ & $1 \cdot 16(0 \cdot 89,1 \cdot 51)$ & $1.24(0.97,1.60)$ \\
\hline $5+$ & 1.00 & $1 \cdot 18(1 \cdot 01,1 \cdot 39)$ & $1 \cdot 17(0.90,1.53)$ & $1 \cdot 20(0 \cdot 93,1 \cdot 54)$ \\
\hline $6+$ & 1.00 & $99,1 \cdot 37)$ & $1 \cdot 15(0 \cdot 88,1$ & $1 \cdot 18(0 \cdot 92,1 \cdot 52)$ \\
\hline \multicolumn{5}{|c|}{ Fatal coronary heart disease } \\
\hline Model 1 & 1.00 & $0.98(0 \cdot 75,1 \cdot 27)$ & $0.76(0 \cdot 48,1 \cdot 22)$ & $1 \cdot 12(0 \cdot 74,1 \cdot 68)$ \\
\hline 2 & 1.00 & $0.97(0 \cdot 75,1 \cdot 26)$ & 0.79( & $1.64)$ \\
\hline $3+$ & $1 \cdot 00$ & $0.97(0 \cdot 73,1 \cdot 28)$ & $(3,1 \cdot 22)$ & $.60,1 \cdot 51)$ \\
\hline $4+$ & $1 \cdot 00$ & $0.94(0 \cdot 72,1 \cdot 25)$ & $0.69(0 \cdot 41,1 \cdot 16)$ & $0.93(0.59,1 \cdot 48)$ \\
\hline \multicolumn{5}{|c|}{ Total coronary heart disease } \\
\hline Model 1 & 1.00 & $1 \cdot 14(1 \cdot 00,1 \cdot 29)$ & $0.99(0 \cdot 79,1 \cdot 23)$ & $1 \cdot 28(1 \cdot 05,1 \cdot 56)$ \\
\hline 2 & & $1 \cdot 13(1 \cdot 00,1 \cdot 39)$ & & $1 \cdot 24(1 \cdot 02,1 \cdot 51)$ \\
\hline $3+$ & 1.00 & $1 \cdot 14(0 \cdot 99,1 \cdot 31)$ & $1 \cdot 06(0 \cdot 84,1 \cdot 35)$ & $1 \cdot 18(0 \cdot 94,1 \cdot 46)$ \\
\hline $4+$ & 1.00 & $1 \cdot 12(0 \cdot 98,1 \cdot 29)$ & $1 \cdot 03(0 \cdot 81,1 \cdot 30)$ & $1 \cdot 16(0 \cdot 93,1 \cdot 45)$ \\
\hline $5+$ & 1.00 & $1 \cdot 12(0 \cdot 97,1 \cdot 29)$ & $1 \cdot 04(0 \cdot 82,1 \cdot 32)$ & $1 \cdot 11(0 \cdot 89,1 \cdot 38)$ \\
\hline & 1.00 & $1 \cdot 11(0 \cdot 96,1 \cdot 27)$ & $1.02(0 \cdot 81,1 \cdot 30)$ & $1 \cdot 10(0 \cdot 88,1 \cdot 37)$ \\
\hline
\end{tabular}

Model: $1=$ Age, plus body mass index, smoking. $2=1$, plus parental $\mathrm{MI}<60 \mathrm{y}$, past history of hypertension, hypercholesterolaemia, diabetes. $3=2$, plus aspirin (1-6 per week $v$ s 0 or $>6$ ), hormone replacement therapy, past oral contraceptive use. $4=3$, plus alcohol, exercise, trans fatty acids (energy adjusted), quintiles vitamin E. $5=4$, plus breastfed, birth weight, adult height. $6=5$, plus spouses' education.

* Father deceased when cohort member was aged 16 years.

+ Denotes follow up for period 1980-90, when extra study variables used in models 3 and 4 were measured.
756 cases of non-fatal myocardial infarction, 277 cases of fatal coronary heart disease, 510 cases of non-fatal stroke, and 156 cases of fatal stroke. When we limited analysis to this period (table 2), the increased risks observed among the "father deceased" group for non-fatal, fatal and total stroke, non-fatal and total cardiovascular disease, and total coronary heart disease were no longer apparent.

The small but significantly increased risk of total cardiovascular and coronary heart disease in the blue collar and "father deceased" groups was largely due to an increased risk of nonfatal myocardial infarction. The relative risk of non-fatal myocardial infarction and total coronary heart disease fell slightly within the blue collar group when data on body mass index and cigarette smoking were added to the model (table 3). For this group the addition of variables collected in 1980 had little effect on the relative risks, but did widen the confidence intervals because of the smaller numbers of cases in the restricted analysis. The relative risks for outcomes increased slightly among the farmer group but fell markedly among the "father deceased" group.

When we refined the categories of white collar and blue collar into the occupational classification scheme of Edwards ${ }^{17}$ as shown in table 4 (apart from the "farmer group" for which these data are given in table 3), we observed the largest increase in risks found in the present analyses. The relative risk of total coronary heart disease was 1.53 (95\% CI 1.09, $2 \cdot 16)$ and that of non-fatal myocardial infarction was $1.67(95 \%$ CI $1 \cdot 11,2 \cdot 53)$ in the lowest (labourer) compared with the highest (professional) childhood socioeconomic group after adjustment for all potential confounding variables. In multivariate analysis a significant trend of increased risk of non-fatal myocardial infarction $(p=0.045)$ with decreased childhood socioeconomic status was observed.

total coronary heart, and cardiovascular disease in the range of $15-30 \%$, compared with women from white collar childhood backgrounds. In the same model, women from "farmer" childhood backgrounds had an apparent small but non-significant decrease in the risk of fatal coronary heart disease $(R R=0.69 ; 95 \%$ CI $0 \cdot 46,1 \cdot 05)$ and fatal cardiovascular disease $(\mathrm{RR}=0 \cdot 81 ; 95 \%$ CI $0 \cdot 59,1 \cdot 11)$. We also observed an apparent small but non-significant elevation in risk of non-fatal stroke $(R R=1 \cdot 22$; $95 \% \mathrm{CI} 0 \cdot 93,1 \cdot 60)$ and total stroke $(\mathrm{RR}=1 \cdot 17$; $95 \%$ CI $0.91,1.47$ ) in the "father deceased" group.

Between 1980 and 1990 we documented

\section{Discussion}

In this prospective cohort study we observed a small but significantly increased risk of total cardiovascular disease (defined as coronary heart disease and stroke) among women from blue collar childhood backgrounds compared with women from white collar childhood backgrounds. The apparent small increase in risk lower socioeconomic backgrounds was due largely to an excess of coronary heart disease. While the larger number of cases of heart disof cardiovascular disease among women from

Table 4 Relative risks (95\% CI) of coronary heart disease (CHD) by disaggregated childhood socioeconomic status in multivariate analysis

\begin{tabular}{|c|c|c|c|c|c|c|c|}
\hline & Professional & Manager & Clerical & $\begin{array}{l}\text { Skilled } \\
\text { blue collar }\end{array}$ & $\begin{array}{l}\text { Semi-skilled } \\
\text { blue collar }\end{array}$ & Domestic & Labourer \\
\hline $\begin{array}{l}\text { No of women } \\
\text { Person years } \\
\text { exposure }\end{array}$ & $\begin{array}{r}12377 \\
169198\end{array}$ & $\begin{array}{r}17171 \\
234803\end{array}$ & $\begin{array}{r}11677 \\
159576\end{array}$ & $\begin{array}{r}27203 \\
371093\end{array}$ & $\begin{array}{r}17432 \\
238297\end{array}$ & $\begin{array}{r}6100 \\
83257\end{array}$ & $\begin{array}{r}3661 \\
49868\end{array}$ \\
\hline $\begin{array}{l}\text { Total CHD } \\
\text { Model 6+ } \\
\text { Fatal CHD } \\
\text { Model 4+ } \\
\text { Non-fatal MI } \\
\text { Model } 6+\end{array}$ & $\begin{array}{l}1.00 \\
1.00\end{array}$ & $\begin{array}{c}1 \cdot 13 \\
(0 \cdot 87,1 \cdot 47) \\
0 \cdot 70 \\
(0 \cdot 43,1 \cdot 15) \\
1 \cdot 35 \\
(0 \cdot 94,1 \cdot 84)\end{array}$ & $\begin{array}{c}0 \cdot 87 \\
(0 \cdot 64,1 \cdot 18) \\
0 \cdot 69 \\
(0 \cdot 40,1 \cdot 20) \\
0 \cdot 93 \\
(0 \cdot 65,1 \cdot 34)\end{array}$ & $\begin{array}{c}1 \cdot 12 \\
(0 \cdot 88,1 \cdot 42) \\
0 \cdot 69 \\
(0 \cdot 44,1 \cdot 07) \\
1 \cdot 32 \\
(0 \cdot 99,1 \cdot 77)\end{array}$ & $\begin{array}{c}1 \cdot 02 \\
(0 \cdot 79,1 \cdot 32) \\
0 \cdot 69 \\
(0 \cdot 43,1 \cdot 12) \\
1 \cdot 19 \\
(0 \cdot 87,1 \cdot 63)\end{array}$ & $\begin{array}{c}1 \cdot 26 \\
(0 \cdot 92,1 \cdot 73) \\
0 \cdot 85 \\
(0 \cdot 46,1 \cdot 55) \\
1 \cdot 46 \\
(1 \cdot 01,2 \cdot 11)\end{array}$ & $\begin{array}{c}1 \cdot 53 \\
(1 \cdot 09,2 \cdot 16) \\
1 \cdot 30 \\
(0 \cdot 70,2 \cdot 41) \\
1 \cdot 67 \\
(1 \cdot 11,2 \cdot 53)\end{array}$ \\
\hline
\end{tabular}

Model: see table 3 . $\mathrm{MI}=$ myocardial infarction. 
ease than stroke may account for this, it should also be noted that risk factors for myocardial infarction and stroke differ. ${ }^{34}$

The small increase in risk for women in the blue collar group was not explained fully by differences in confounding or intermediate variables. In particular, when we disaggregated the childhood socioeconomic categories and compared the most disadvantaged with the most advantaged group in multivariate analysis, there was an excess risk of total coronary heart disease and non-fatal myocardial infarction in the range of $50-70 \%$. This excess is similar to that reported for middle aged men in the $\mathrm{Ku}-$ opio study, ${ }^{35}$ which used paternal occupation in association with other parental variables to assign childhood socioeconomic status within three categories. In that study, adjustment for cardiovascular risk factors and adult socioeconomic status weakened but did not eliminate the association between childhood socioeconomic status and prevalent ischaemic heart disease.

When we adjusted associations for differences in cardiovascular risk factors and sociodemographic variables, the risk estimates were attenuated for women whose fathers were deceased but were increased among women in the farmer group. This raises the possibility that some of the increased incidence of coronary heart disease in the former and decreased incidence in the latter were due to differences in risk factors in adulthood which were associated with childhood socioeconomic status.

Recent reviews have examined longitudinal and case-control studies of the association between early life environment and adult cardiovascular disease, ${ }^{1136}$ and concluded that the observed associations were compromised by inadequate handling of confounding variables, in particular of adult socioeconomic status. This may lead to an overestimation of the risk associated with lower childhood socioeconomic status. Our analysis was performed among a cohort of female registered nurses, a relatively homogeneous group for adult socioeconomic status. In addition, we adjusted for differences in the socioeconomic status of spouses of the cohort members.

It is possible that the effect of differences in childhood socioeconomic status among women in this study was confounded by the socioeconomic status of their spouses and hence by the economic wellbeing of the woman's domestic arrangements. While educational attainment is an important variable in assessing adult socioeconomic status, ${ }^{19}$ some caveats apply in assessing its validity in this analysis. We assessed spouses' educational status only in 1992. For some, this person may not be the same spouse preceding the woman's cardiovascular event. No information on spouses' educational attainment was available for cases of fatal cardiovascular disease. Finally, almost $17 \%$ of the cohort were either unmarried in 1992 or gave no reply to this question. However, inclusion of this variable in multivariate modelling did not materially affect the risk estimates.

We used the father's and not the mother's occupation to determine childhood socioeconomic status. ${ }^{37}$ An analysis of the distribution of mother's listed occupation in this cohort showed that over $66 \%$ were employed in domestic duties and analyses of models based solely on mother's occupation showed no increased risk for any group.

A recent case-control study suggested differences in coronary heart disease rates among adult men from different (adult) socioeconomic groups could be explained by differences in serum high density lipoprotein cholesterol. ${ }^{18}$ The possible role of adult blood lipid subfractions in accounting for the differences in the present study could not be determined, as haematological variables were not ascertained in this cohort.

It has been argued that early life environmental factors such as fetal nutrition or being breastfed in infancy might have long term effects on the risk of cardiovascular disease. Babies who are small at birth or during infancy have increased rates of cardiovascular disease and non-insulin dependent diabetes mellitus as adults. ${ }^{38}$ Adult height, which is positively related to childhood nutritional status and inversely related to the adult risk of cardiovascular disease, ${ }^{39}$ has been used in a number of studies as a proxy for childhood socioeconomic experience. ${ }^{40.42}$ However, inclusion of these variables in multivariate modelling did not explain the observed associations between childhood socioeconomic status and cardiovascular outcomes among women from blue collar childhood backgrounds.

The associations observed in this cohort may have been due to unequal access to medical intervention in some groups when cardiovascular disease symptoms such as angina pectoris first appeared. While this potential source of bias might be particularly important in a nation without universal health care, when we analysed the rate of coronary artery bypass grafting, women from blue collar childhood backgrounds were somewhat more likely to have had this procedure after adjustment for age $(\mathrm{RR}=1 \cdot 19 ; 95 \%$ CI $1 \cdot 02,1 \cdot 39)$. This may explain, at least partly, the apparently stronger association between lower childhood socioeconomic status and incidence of myocardial infarction than mortality from coronary heart disease. Although nurses from lower childhood socioeconomic backgrounds were more likely to suffer a myocardial infarct, to the extent that medical interventions (such as bypass grafting) were effective, any association between childhood socioeconomic status and mortality in this cohort may have been underestimated.

All participants in the cohort were selected from registers of the State Boards of Nursing. Thus, all cohort members were health professionals with recognised nursing credentials. If women from lower socioeconomic backgrounds were under-represented in this cohort, then our ability to detect a stronger effect of poverty or absolute deprivation during childhood on risk of coronary heart disease in adulthood would be limited.

In summary, our findings indicate that low childhood socioeconomic status is associated 
with a small but significant increase in risk of coronary heart disease in middle aged women. The increased risk among women from blue collar backgrounds was not fully explained by differences in a large number of risk factors for cardiovascular disease. This was particularly so for those women from the most disadvantaged childhood socioeconomic background. Although the magnitude of the association is modest, the public health impact could be substantial. ${ }^{43}$ Increased preventive efforts targetting modifiable cardiovascular risk factors among children and adolescents before risk behaviour becomes established has been advocated. ${ }^{44}$ These data suggest that such effort should be targetted towards the socioeconomically disadvantaged.

Our results suggest that neither differences in fetal nutrition as evidenced by birth weight, nor differences in adult environmental circumstances, could explain the association between childhood socioeconomic circumstances and risk of adult cardiovascular disease observed in our cohort. There is some evidence linking nutritional status in early and middle childhood years to the risk of subsequent cardiovascular disease. ${ }^{4546}$ If these findings are confirmed, nutritionally based intervention programmes in childhood may offer a means of addressing the imbalance in the later life risk of cardiovascular disease.

A hypothesis worthy of investigation is whether directly addressing socioeconomic deprivation in childhood might be of added effectiveness in reducing the risk of coronary heart disease in later life.

Supported by research grants (HL 24074, HL 34594, CA 40935 and CA 40356) from the National Institutes of Health, USA.

1 Fox AJ, Goldblatt PO, Jones DR. Social class mortality differentials: artefact, selection or life circumstances? In RG Wilkinson ed. Class and health: research and longitudinal data. London: Tavistock, 1986

2 Carstairs V, Morris R. Deprivation: explaining differences in mortality between Scotland, England and Wales. $B M F$ 1989;299:886-9.

3 Williams FLR, Lloyd O. Cerebrovascular disease in Scotland during 1959 to 1983: its geographical distribution and associations. Community Medicine 1989;11:306-15.

4 Marmot M. Socioeconomic determinants of CHD mortality. Int $\mathcal{F}$ Epidemiol 1989;18:3(suppl 1):S196-202.

5 Shaper AG, Phillips AN, Pocock SJ, Walker M, Macfarlane PW. Risk factors for stroke in middle aged British men. PW. Risk factors for st
$B M \mathcal{1}$ 1991;302:1111-5.

6 Kawachi I, Marshall S, Pearce N. Social class inequalities in the decline of coronary heart disease among New Zealand men, 1975-1977 to 1985-1987. Int F Epidemiol

7 Baker IA, Sweetnam PM, Yarnell JWG, Bainton D, Elwood PC. Haemostatic and other risk factors for ischaemic heart disease and social class: evidence from the Caerphilly and Speedwell studies. Int $\mathcal{F}$ Epidemiol 1988;17:759-65.

8 Stamler R, Shipley M, Elliott P, Dyer A, Sans S, Stamler J. Higher blood pressure in adults with less education. Some explanations from INTERSALT. Hypertension 1992; 19:237-41.

9 Gliksman MD, Dwyer T, Wlodarczyk J. Differences in modifiable cardiovascular disease risk factors in Australian schoolchildren: the results of a nationwide survey. Prev Med 1990;19:291-304

10 Gliksman MD, Lazarus R, Wilson A. Differences in serum lipids in Australian children with age, sex, socioeconomic status and ethnic origin: is diet responsible? Int $\mathcal{F}$ Epidemiol

11 Elford J, Whincup P, Shaper AG. Early life experience and adult cardiovascular disease: longitudinal and case-control adult cardiovascular disease: longitudinal

12 Roudies. Int $f$ Epidemiol 1991,20.833-44. cupational attitudes and occupational characteristics. Ann Arbor, MI: Survey Research Centre; Institute for Social Research, 1969 .

13 Manson JE, Rimm EB, Stampfer MJ, et al. Physical activity and incidence of non-insulin-dependent diabetes mellitus in women. Lancet 1991;338:774-8

14 Willett WC, Sampson L, Browne ML, et al. The use of a self-administered questionnaire to assess diet four years in the past. Am $\mathcal{F}$ Epidemiol 1988;127:188-99.

15 Willett WC. Nutritional epidemiology. New York: Oxford University Press, 1989

16 Edwards AM. US census of population, 1940: Comparative occupational statistics, 1870-1940. Washington, DC: US Government Printing Office, 1943.

17 Liberatos P, Link BG, Kelsey JL. The measurement of social class in epidemiology. Epidemiol Rev 1988;10:87-121.

18 Hebert PR, Buring JE, O'Connor GT, Rosner B, Hennekens $\mathrm{CH}$. Occupation and risk of nonfatal myocardial infarction. Arch Intern Med 1992;152:2253-7.

19 Winkleby MA, Jatulis DE, Frank E, Fortmann SP. Socioeconomic status and health: how education, income, and occupation contribute to risk factors for cardiovascular disease. Am 7 Public Health 1992;82:816-20.

20 Willett WC, Stampfer MJ, Bain C, Rosner B, Speizer FE. Cigarette smoking, relative weight, and menopause. $\mathrm{Am}$ f Epidemiol 1983;117:651-8.

21 Paffenbarger RS Jr, Blair SN, Lee IM, Hyde RT. Measurement of physical activity to assess health effects in freeliving populations. Med Sci Sports Exer 1993;25:60-70.

22 Washburn RA, Adams LL, Haile GT. Physical activity assessment for epidemiologic research: the utility of two simplified approaches. Prev Med 1987;16:636-46.

23 Washburn RA, Goldfield SRW, Smith KW, McKinlay JB. The validity of self-reported exercise-induced sweating as a measure of physical activity. Am f Epidemiol 1990;132: a measure

24 Colditz GA, Willett WC, Stampfer MJ, et al. The influence of age, relative weight, smoking, and alcohol intake on the
reproducibility of a dietary questionnaire. Int $\mathcal{F}$ Epidemiol reproducibility of

25 Giovannucci E, Colditz GA, Stampfer MJ, et al. The assessment of alcohol consumption by a simple self-administered questionnaire. $A m$ f Epidemiol 1991;133: 810-17.

26 Willett WC, Stampfer MJ, Manson JE, et al. Intake of trans fatty acids and risk of coronary heart disease among women. Lancet 1993;341:581-5.

27 Stampfer MJ, Hennekens CH, Manson JE, et al. A prospective study of vitamin $\mathrm{E}$ consumption and risk of coronary disease in women. $N$ Engl 7 Med 1993.328. 1444-9.

28 Stampfer AG, Colditz GA, Willett WC, Speizer FE, Hennekens $\mathrm{CH}$. A prospective study of moderate alcohol consumption and the risk of coronary disease and stroke in women. $N$ Engl f Med 1988;319:267-73.

29 World Health Organisation. IHD registers: report of the Fifth Working Group. Copenhagen: WHO, 1971 .

30 Willett WC, Green A, Stampfer MJ, et al. Relative and absolute excess risks of coronary heart disease among women who smoke cigarettes. $N$ Engl F Med 1987;317: 1303-9.

31 Colditz GA, Bonita R, Stampfer MJ, et al. Cigarette smoking and risk of stroke in middle-aged women. $N$ Engl $\mathcal{F}$ Med 1988;318:937-41.

32 Manson JE, Stampfer MJ, Colditz GA, et al. A prospective study of aspirin use and primary prevention of cardiovascular disease in women. $7 A M A$ 1991;266:521-7.

33 Stampfer MJ, Colditz GA, Willett WC, et al. Postmenopausal estrogen therapy and cardiovascular disease: ten-year follow-up from the Nurses' health study. $N$ Engl ten-year follow-up from the
M Med 1991;325:756-62.

34 Reed DM. The paradox of high risk of stroke in populations with low risk of coronary heart disease. Am $\mathcal{f}$ Epidemiol $1990 ; 131: 579-88$

35 Kaplan GA, Salonen JT. Socioeconomic conditions in childhood and ischaemic heart disease during middle age. BMF 1990;301:1121-3.

36 Hill AB. The environment and disease: association or causation? Proceedings of the Royal Society of Medicine 1965;58 295-300

37 Haug MR. Measurement in social stratification. Annual Revues in Sociology 1977;3:51-77.

38 Barker DJP, Gluckman PD, Godfrey KM, Harding JE, Owens JA, Robinson JS. Fetal nutrition and cardiovascular disease in adult life. Lancet 1993;341:938-41.

39 Yarnell JW, Limb ES, Layzell JM, Baker IA. Height: a risk marker for ischaemic heart disease: prospective results from the Caerphilly and Speedwell heart disease studies. Eur Heart $\mathcal{F}_{1992 ; 13: 1602-5 .}$

40 Walker M, Shaper AG, Phillips AN, Cook DG. Short stature, lung function and risk of a heart attack. Int $\mathscr{f}$ Epidemiol 1989;18:602-6.

41 Nystrom Peck AM, Vagero DH. Adult body height, selfperceived health and mortality in the Swedish population. 7 Epidemiol Community Health 1989;43:380-4.

42 Marmot MG, Shipley MJ, Rose G. Inequalities in death specific explanations of a general pattern. Lancet 1984; 003-6.

43 Rose G. Mass prevention: population-directed approach Acta Cardiol 1988;29(suppl):131-9.

44 Report of the expert panel on blood cholesterol in children and adolescents, Bethesda, MA: National Institutes of Health Publication 91-2732, HHS, USA, 1991.

45 Ariouat JF, Barker DJ. The diet of girls and young women at the beginning of the century. Nutr Health 1993;9:15-23.

46 Fall $\mathrm{CH}$, Barker DJ, Osmond C, et al. Relation of infan feeding to adult serum cholesterol concentration and death from ischaemic heart disease. BMF 1992;304:801-5. 